\title{
"Mi Dragón Dormido", herramienta terapéutica y psicoeducativa para la revelación del diagnóstico de VIH/SIDA a niños y prevención del estigma social
}

\section{"Mi Dragón Dormido" ("My Sleeping Dragon"), therapeutic and psychoeducational tool for the HIV/AIDS diagnosis disclosure to children and prevention of social stigma}

\author{
Yolima Alarcón-Vásquez ${ }^{1}$, Ana M. Trejos-Herrera ${ }^{2 *}$ y Marly J. Bahamón ${ }^{3}$
}

1Facultad de Ciencias Jurídicas y Sociales, Universidad Simón Bolívar, Barranquilla, Colombia. http://orcid.org/0000-0001-6357-8908.
2Departamento de psicología, Universidad del Norte, Barranquilla, Colombia. https://orcid.org/0000-0002-2658-6535.
${ }^{3}$ Facultad de Ciencias Jurídicas y Sociales, Universidad Simón Bolívar, Barranquilla, Colombia. http://orcid.org/0000-0003-2528-994X.

Los autores declaran no tener conflicto de intereses

Fuente de Financiamiento: Dirección de Investigación de la Universidad del Norte.

Recibido: 28 de abril de 2021 / Aceptado: 6 de julio de 2021

\section{Resumen}

Introducción: La Organización Mundial de la Salud y la Académica Americana de Pediatría sugieren revelar el diagnóstico de VIH a niños. Sin embargo, esto no es una práctica consolidada en Colombia; a menudo esto ocurre porque los cuidadores no tienen una metodología adecuada para llevar a cabo este proceso. Objetivo: Se presenta la evaluación de la eficacia de la historia "Mi Dragón Dormido" para el proceso de educación y revelación del diagnóstico de VIH/SIDA a niños. Método: Mediante muestreo no probabilístico intencional; se administraron entrevistas semiestructuradas a 40 niños, seropositivos $(n=20)$ y seronegativos $(n=20)$ para VIH/SIDA. Se trató de un estudio cualitativo y diseño sistemático. Se realizó análisis cualitativo mediante el software NVivo 10 con codificación tipo Nodos de Árbol. Resultados: Los datos cualitativos aportaron aproximaciones necesarias para mejorar el contenido y el diseño de la herramienta e indicaron que refleja la realidad de los niños y permite identificar temores y preguntas frecuentes frente a la condición crónica de salud del VIH. Conclusiones: Estos resultados aportan información importante a considerar en el proceso de revelación del diagnóstico y su manejo por parte del personal de salud.

Palabras clave: VIH; diagnóstico; niños; revelación de diagnóstico; psicoeducación.

\section{Abstract}

Background: The World Health Organization and the American Academy of Pediatrics suggest disclose the HIV diagnosis to children. However, the disclosure of HIV/AIDS diagnosis to children and adolescents, it is not a consolidated practice in Colombia, often this occurs because caregivers do not have an adequate methodology to carry out this process. Aim: We present the efficiency components validation of "Mi dragon Dormido" history in the educational process and revelation of AIDS diagnosis to boys and girls. Method: By means of purposive non-probability sampling, semi-structured interviews were conducted with 40 children, with an equal number of children who were seropositive $(n=20)$ and seronegative $(n=20)$ for HIV/ AIDS. A qualitative study with the approach of grounded theory and systematic design was conducted. We conducted the qualitative study through the NVivo software, with the codification type being Tree Nodes. Results: The qualitative data provided necessary approximations to improve the content and design of the tool and showed that it reflects the reality of children and allows them to identify frequent fears and questions regarding to chronic health condition of HIV. Conclusions: These results provide important information to be considered in the process of diagnosis revelation and its management by health personnel.

Keywords: HIV; diagnosis; children; disclosure; psychoeducation. 
crónica de salud. Además, para los niños seronegativos para VIH/SIDA la herramienta pretende educar en los conceptos básicos de la misma y generar sensibilidad, mayor comprensión y percepción de apoyo social hacia las personas que han recibido este diagnóstico.

El objetivo de este estudio fue realizar una validación técnica y con población de la herramienta de apoyo "Mi Dragón Dormido" y así poder determinar si la herramienta es atractiva, comprensible y si favorece el involucramiento, aceptación e inducción a la acción en niños bajo 15 años de edad. De esta manera se pretendió desarrollar una herramienta psicoeducativa que puede ser utilizada por padres, cuidadores, profesionales de la salud y cuidadores de niños y adolescentes con la condición crónica de salud de infección por VIH y, por otra parte, un aporte a combatir la discriminación asociada al estigma social de esta condición de salud. relevancia si se tiene en cuenta que de acuerdo con la $\mathrm{ONUSIDA}^{3}$, en el 2014 se produjeron en América Latina 2.000 nuevas infecciones por el VIH en niños.

Estudios revisados indican que los niños seropositivos para VIH/SIDA están expuestos a diversas razones relacionadas al ocultamiento del diagnóstico: temor que la comunicación del diagnóstico pueda causar daño psicológico, estrés o angustia emocional, temor a que el niño revele el diagnóstico a otras personas y exponerlos a situaciones de discriminación, la edad insuficiente, considerando al niño muy joven para conocer el diagnóstico, el sentimiento de culpabilidad de los padres por haber transmitido el diagnóstico, falta de conocimiento de cómo revelar el diagnóstico por parte de los padres y/o cuidadores ${ }^{4-14}$.

Profesionales de la salud, padres y/o cuidadores tienden a postergar la entrega del diagnóstico de VIH a los niños no sólo por las razones expresadas anteriormente, sino, también porque no disponen de una metodología adecuada para llevar a cabo este proceso, y evitan explicarle el diagnóstico al niño, o le mencionan otros diagnósticos menos severos, es sostenida por el principio bioético de la No Maleficencia, lo cual termina causando daño al niño ${ }^{15,14}$.

La historia o herramienta "Mi Dragón Dormido"16 pretende ser una opción lúdica, adecuada al nivel de desarrollo cognitivo de niños bajo 15 años de edad para comprender, asimilar y aceptar el diagnóstico de VIH/ SIDA informándolo de una manera lúdica utilizando la metáfora del dragón, el cual representa el virus del VIH. Esta herramienta sería complementaria al Modelo Clínico "DIRÉ", el cual demostró eficacia en la normalización del ajuste psicológico y mantenimiento del cumplimiento terapéutico en población infantil afectada con la infección por $\mathrm{VIH} / \mathrm{SIDA}^{17} \mathrm{y}$, busca que el niño con infección por VIH se identifique con el personaje principal debido a que éste atraviesa por experiencias muy similares a las de cualquier niño diagnosticado con esta condición

\section{Método}

\section{Diseño}

Estudio cualitativo que utilizó procedimientos de fundamentación, contenido, recogida y análisis de información propios del enfoque de teoría fundamentada con diseño Sistemático ${ }^{18}$. De acuerdo con esto, los datos provenientes de las entrevistas con los niños y adolescentes seropositivos y seronegativos para VIH/ SIDA se categorizaron con codificación abierta donde se fragmentó la información para conformar las categorías descriptivas y luego se organizaron las categorías resultantes en un modelo de interrelaciones (codificación axial) que permitió generar una categoría central que se relacionó de manera sistemática con las demás (codificación selectiva) ${ }^{19}$.

\section{Participantes}

Mediante muestreo no probabilístico intencional se seleccionaron 20 niños y adolescentes, con diagnóstico de infección por VIH/SIDA, cuyo criterio de inclusión principal fue el conocimiento de su diagnóstico, pertenecientes a seis instituciones prestadoras de servicios de salud y, 20 niños y adolescentes escolarizados sin diagnóstico de VIH/SIDA; ambos con edades comprendidas entre los 6 y 17 años de edad.

El $65 \%$ de los participantes con edades comprendidas entre los 12 y 14 años de edad con una media de edad de 12 años; 50\% hombres, 50\% mujeres. El 85\% de los niños pertenecen al régimen subsidiado de salud; $70 \%$ de ellos han sido atendidos en una o dos instituciones prestadoras de servicios de salud y $90 \%$ de ellos conoció su diagnóstico a través del Modelo Clínico "DIRÉ". Se entrevistaron 20 niños y adolescentes seronegativos para VIH/SIDA, con edades comprendidas entre 7 y 9 años, 10 y 12 años 
y entre 13 y 15 años, con un 30\%, respectivamente, y una media de edad de 11 años; $60 \%$ eran del sexo femenino.

\section{Consideraciones éticas}

Se tuvieron en cuenta los aspectos éticos de la investigación con seres humanos considerados en la Resolución $\mathrm{N}^{\circ} 008430$ de 1993 del Ministerio de Salud de Colombia por la cual se establecen las normas científicas, técnicas y administrativas para la investigación en salud y, la Ley 1090 de 2006 o Ley del Psicólogo en Colombia que comprende el secreto profesional, derecho a la no participación y retiro, consentimiento informado y la devolución de resultados. Se solicitó firma del consentimiento informado a los padres de los sujetos participantes por ser menores de edad. Del mismo modo se solicitó firma del asentimiento informado para los menores de edad con la respectiva explicación verbal del proceso de investigación.

\section{Técnicas e instrumentos de recolección de información}

Con base en los criterios de la guía metodológica y video de validación de materiales IEC de UNICEF $^{20}$, se diseñó una entrevista semiestructurada de 15 preguntas para evaluar cinco componentes de eficacia: atracción, comprensión, involucramiento, aceptación e inducción a la acción de la herramienta/historia "Mi Dragón Dormido" (Tabla 1). Se finalizó con una pregunta abierta para valorar la utilidad de la herramienta en procesos de revelación del diagnóstico de VIH/SIDA a niños y adolescentes. La entrevista fue revisada y validada por criterio de 10 jueces expertos en las áreas de Psicología y Medicina.
La validación de la atracción consistió en averiguar si la herramienta llama la atención en cuanto a colores, diseño y formato, identificar el personaje e imagen favorita de la historia y además conocer cuál es la definición que los niños y niñas otorgan a la expresión "Mi Dragón Dormido”. La validación de comprensión intentó identificar si quedan claros los contenidos y mensajes de la herramienta. La validación del involucramiento buscó determinar si favorece la identificación con lo que proponen los mensajes y las imágenes. La validación de la aceptación permitió determinar si el público objetivo acepta las propuestas o acciones contenidas en los mensajes, además de confirmar que nada genere alguna indisposición en la población objetivo y la aceptación plena del enfoque, los contenidos y el lenguaje utilizado. Finalmente, la validación de la inducción a la acción buscó comprobar si el cambio de comportamiento o actitud propuesto es identificado y posible de lograr en la población objetivo.

Se procedió inicialmente con la lectura de la herramienta "Mi Dragón Dormido" en forma individual con los niños, niñas y adolescentes seropositivos y seronegativos para la infección por VIH/SIDA. La herramienta fue impresa en formato doble cara para facilitar la lectura, tanto del entrevistador como del sujeto participante y, posteriormente, se realizó la entrevista semiestructurada.

\section{Método de análisis y procesamiento de los datos}

Las informaciones obtenidas en las entrevistas con los niños y adolescentes fueron sometidas a análisis cualitativo, con apoyo del software Nvivo 10. Se inició un proceso de codificación a través de Nodos; los cuales

Tabla 1. Entrevista semiestructurada de los componentes de eficacia

Componente 1. Evaluación de la atracción

Componente 2. Evaluación de la comprensión

Componente 3. Evaluación del involucramiento

Componente 4. Evaluación de la aceptación

10. ¿Qué no te gusto de la historia y por qué?

11. ¿Hubo algo que te molestara de las imágenes y por qué?

12. ¿Piensas que esta historia podría ser utilizada en una clase de ciencias? / ¿Sería agradable o desagradable usarla en la clase de ciencias?

Componente 5. Evaluación de la inducción a la acción

13. ¿Consideras que la historia propone algún cambio en el comportamiento de los niños? ¿Cuál?

14. ¿Qué reflexión u opinión puede tener un niño cuando termine de leer esta historia?

15. ¿Es posible que algún niño ponga en práctica algo que le haya enseñado la historia? ¿Qué haría ese niño? 
son recipientes para las codificaciones que permitieron recopilar material relacionado en un lugar, de modo que se pueden buscar patrones e ideas emergentes.

Para el procedimiento se empleó una codificación tipo Nodos de Árbol, donde los nodos principales que surgieron de los componentes de eficacia propuestos por $\mathrm{UNICEF}^{20}$, agruparon otros nodos secundarios que representan las categorías de cada uno de los cinco componentes y, éstos a su vez, agrupan otros nodos terciarios que representan las subcategorías. Los nodos terciarios o subcategorías emergieron tras realizar una codificación abierta donde se identificaron las unidades de análisis que emergieron de la lectura detallada de las entrevistas y de la comparación constante de las unidades de análisis. Conforme fue avanzado el proceso de codificación se revisaron nuevos segmentos de datos y los anteriores segmentos para continuar conectando conceptualmente las unidades de análisis, generando más categorías o consolidando las anteriores. Los segmentos de datos que compartían naturaleza, significado y características se asignaron en el mismo nodo.

\section{Resultados}

\section{Validación de la atracción}

Para la mayoría de los niños y adolescentes entrevistados el personaje favorito fue "Alejandra", la protagonista debido a su capacidad de resiliencia frente a las situaciones adversas de su diagnóstico, resaltan la valentía de este personaje, que sigue adelante a pesar de todo. El personaje "David" ejemplifica para los niños (as) el principio de la igualdad y no discriminación a los niños afectados con el VIH/SIDA (Tabla 2).

La mayoría de los niños identificaron como su imagen favorita la de los "Niños jugando en el parque" debido a que refleja el valor de la amistad y el principio de la igualdad y a la no discriminación. Un personaje clave para los niños con el diagnóstico es la "Doctora Esperanza" y un personaje clave para los niños sin el diagnóstico es la "Abuela", de ahí que las imágenes favoritas de los niños se centren en estos personajes (Tabla 2).

Los niños seropositivos para VIH/SIDA identifican claramente que el dragón representa la enfermedad o virus del VIH y, puntualmente indican que es la medicación lo que lo mantiene dormido, controlado y que permite llevar una vida normal. Los testimonios de los menores muestran que han interiorizado la información que pretendía la metáfora del dragón dormido puesto que mencionan que si el dragón despierta debido a la no toma de la medicación puede atacar las defensas, enfermar causando daño y llevar al desarrollo del SIDA. Los niños seronegativos para VIH/SIDA opinan que el dragón dormido es una metáfora que se usa para representar a la enfermedad o virus del VIH para no causar un impacto emocional negativo a los niños con este diagnóstico (Tabla 2).

\section{Validación de la comprensión}

Todos los niños identificaron que el Dragón Dormido es una enfermedad o es el virus del VIH que está escondido, dormido o controlado con los medicamentos que mantienen al virus pasivo. Para los niños seronegativos para VIH/SIDA es una forma sutil y suave de revelar el diagnóstico a un niño (Tabla 3 ).

El mensaje o moraleja para los niños seronegativos para VIH/SIDA se relaciona con el principio de igualdad o no discriminación a los niños con este diagnóstico y el aprendizaje de la capacidad de resiliencia. Además, la herramienta demostró utilidad en el ámbito de la prevención primaria del VIH. Se resalta que el término inmunodeficiencia es difícil de comprender para algunos niños (Tabla 3).

\begin{tabular}{|c|c|c|}
\hline Categoría & Niños seropositivos para VIH/SIDA & Niños seronegativos para VIH/SIDA \\
\hline \multicolumn{3}{|c|}{ Validación de la atracción } \\
\hline \multirow[t]{3}{*}{ Personaje favorito } & Alejandra: resiliencia y adherencia terapéutica & Alejandra: resiliencia \\
\hline & Doctora Esperanza: principio bioético de beneficencia & David: principio de igualdad y no discriminación \\
\hline & David: principio de igualdad y no discriminación. & Abuela: características de "abuelidad" \\
\hline \multirow[t]{2}{*}{ Imagen favorita } & "Niños jugando en el parque": Valor de la amistad & "Niños jugando en el parque": Valor de la amistad \\
\hline & "Alejandra y la Doctora Esperanza" & "Alejandra y su abuela Ilorando": Protección y Apoyo Emocional \\
\hline Dragón dormido & $\begin{array}{l}\text { Representa el virus del VIH y la medicación lo mantiene dormido, } \\
\text { controlado y permite llevar una vida normal. Si el Dragón despierta } \\
\text { debido a la no toma de la medicación, puede atacar las defensas, } \\
\text { enfermar causando daño y llevar al desarrollo del SIDA }\end{array}$ & $\begin{array}{l}\text { Es una metáfora que se usa para representar al virus del VIH. Al- } \\
\text { gunos consideran que los niños con VIH son víctimas del error de } \\
\text { sus padres }\end{array}$ \\
\hline
\end{tabular}


Tabla 3. Validación del componente de comprensión

\begin{tabular}{|c|c|c|}
\hline Categoría & Niños seropositivos para VIH/SIDA & Niños seronegativos para VIH/SIDA \\
\hline \multicolumn{3}{|c|}{ Validación de la comprensión } \\
\hline \multirow[t]{4}{*}{ Mensaje de la historia } & Importancia de la adherencia terapéutica & Principio de igualdad o no discriminación \\
\hline & Resiliencia & Resiliencia \\
\hline & Confidencialidad de la información del diagnóstico & Adherencia terapéutica \\
\hline & & Prevención de la infección por VIH \\
\hline \multirow[t]{3}{*}{ Términos sin comprensión } & Discriminación & Inmunodeficiencia \\
\hline & Inmunodeficiencia & Formas de adquirir y no adquirir el VIH \\
\hline & Formas de adquirir y no adquirir el VIH & \\
\hline
\end{tabular}

Tabla 4. Validación del componente de involucramiento

\begin{tabular}{|c|c|c|}
\hline Categoría & Niños seropositivos para VIH/SIDA & Niños seronegativos para VIH/SIDA \\
\hline \multicolumn{3}{|l|}{ Validación del Involucramiento } \\
\hline Sentimientos & $\begin{array}{l}\text { Sentimientos de normalidad e identificación con el personaje } \\
\text { principal }\end{array}$ & $\begin{array}{l}\text { Motivación de ayuda a niños seropositivos para VIH, apren- } \\
\text { dieron la importancia de la igualdad y comprensión de la } \\
\text { enfermedad del VIH }\end{array}$ \\
\hline \multirow[t]{3}{*}{ Consejos para Alejandra } & Adherencia terapéutica & Adherencia terapéutica \\
\hline & Resiliencia & Resiliencia \\
\hline & Confidencialidad de la información del diagnóstico & \\
\hline Perspectiva de futuro para Alejandra & Perspectiva positiva de futuro & Perspectiva de futuro positiva \\
\hline
\end{tabular}

\section{Validación del involucramiento}

Los niños manifestaron sentimientos de normalidad frente a la lectura de la historia. Los consejos se dirigen básicamente hacia la adherencia terapéutica y a la capacidad de resiliencia como herramienta de defensa de la discriminación. Los niños tienen una perspectiva de futuro positiva para el personaje de "Alejandra"; la visualizan con bienestar general, la proyectan como una joven universitaria que encuentra una cura para el SIDA, cumpliendo sus sueños gracias a su adherencia terapéutica y al apoyo emocional de su familia y amigos (Tabla 4).

\section{Validación de la aceptación}

La mayoría de los niños (as) consideraron que las imágenes eran agradables, claras, acordes con la historia y permitían una mejor comprensión de la misma. La situación e imagen más molesta en la herramienta para los niños es la relacionada con la discriminación de los amigos y amigas de Alejandra por desconocimiento y falta de educación sobre el VIH/SIDA. Un hallazgo importante es que para los niños seropositivos para VIH/SIDA fue molesto, en la narración, la situación del ocultamiento del diagnóstico de infección por VIH/SIDA por parte de la madre al inicio de la historia y, por parte de la abuela cuando el personaje principal empezó a realizar preguntas; en cambio para los niños seronegativos para VIH/SIDA fue molesto, la revelación llevada a cabo por la abuela y la doctora Esperanza (Tabla 5).

Todos los niños consideraron que sería agradable y manifestaron que estarían de acuerdo en que se utilizará la herramienta "Mi Dragón Dormido" en clase de Biología con el objeto de propiciar la igualdad y no discriminación hacia los niños diagnosticados con infección por VIH/ SIDA. No obstante, algunos niños y niñas seronegativos para VIH/SIDA consideraron que debe ser empleada en clases de ética y valores para fomentar la reflexión acerca del tema de la discriminación hacia las personas con diagnóstico de infección por VIH (Tabla 5).

\section{Validación de la inducción a la acción}

Los niños seropositivos para VIH/SIDA mencionaron que los principales cambios de comportamiento o actitudes que se pueden generar a partir de la lectura de la herramienta "Mi Dragón Dormido" son: incremento de la adherencia terapéutica, prevención de la trasmisión de la enfermedad a través de la educación en las vías 
Tabla 5. Validación del componente de aceptación

\begin{tabular}{|c|c|c|}
\hline Categoría & Niños seropositivos para VIH/SIDA & Niños seronegativos para VIH/SIDA \\
\hline \multicolumn{3}{|l|}{ Validación de la aceptación } \\
\hline \multirow[t]{2}{*}{ Situaciones e imágenes molestas } & Discriminación de los amigos y amigas de Alejandra & Discriminación de los amigos y amigas de Alejandra \\
\hline & $\begin{array}{l}\text { Ocultamiento del diagnóstico por parte de la madre y } \\
\text { de la abuela }\end{array}$ & $\begin{array}{l}\text { La revelación llevada a cabo por la abuela y la doctora } \\
\text { Esperanza }\end{array}$ \\
\hline Uso de la historia en clases & Se podría usar en clase de Biología & $\begin{array}{l}\text { Se podría usar en clases de Biología y también de Ética y } \\
\text { Valores }\end{array}$ \\
\hline
\end{tabular}

Tabla 6. Validación del componente de inducción a la acción

\section{Categoría}

Validación de la Inducción a la Acción

Cambio de comportamiento o actitud

\section{Niños seropositivos para VIH/SIDA}

Incremento de la adherencia terapéutica

Prevención de la trasmisión de la enfermedad

Guardar confidencialidad del diagnóstico para evitar la discriminación

Importancia de la aceptación del diagnóstico para favorecer el ajuste psicológico

\section{Niños seronegativos para VIH/SIDA}

Aprendizaje de la igualdad y no discriminación a personas con diagnóstico de infección por VIH/SIDA

La aceptación del diagnóstico por parte del niño afectado para favorecer su ajuste psicológico

Fomento de la adherencia terapéutica en estos niños de transmisión del VIH, guardar confidencialidad del diagnóstico para evitar la discriminación y la importancia de la aceptación del diagnóstico para favorecer el ajuste psicológico. Los niños seronegativos para VIH/SIDA resaltaron que los principales cambios de comportamiento o actitudes que se pueden generar a partir de la lectura de la herramienta son el aprendizaje de la igualdad y no discriminación a personas con diagnóstico de infección por VIH/SIDA (Tabla 6).

Todos los niños consideraron que la herramienta "Mi Dragón Dormido" es útil para llevar a cabo el proceso de revelación del diagnóstico a niños menores de 15 años. Adicionalmente, de acuerdo con sus testimonios, esta herramienta pudiera facilitar el aprendizaje sobre la enfermedad y fomentar la capacidad de resiliencia en estos niños.

\section{Discusión}

Una de las tareas más difíciles para los profesionales de la salud, padres y/o cuidadores es determinar cuándo y cómo se le hablará del diagnóstico de infección por VIH/ SIDA a un niño. En la espera del "momento oportuno" para la revelación, un niño puede alcanzar la adolescencia media y tardía sin aun tener conocimiento de su condición; en muchos casos, esta espera trae como consecuencia que el niño conozca su diagnóstico en formas inadecuadas, lo que termina perjudicando el ajuste psicológico y la adherencia terapéutica del menor ${ }^{10-12}$. La no revelación del diagnóstico también puede generar sentimientos de desconfianza del núcleo familiar y del equipo médico tratante ${ }^{21}$.

Las razones por las cuales se opta por no revelar el diagnóstico de infección por VIH/SIDA a un niño reflejan cuán difícil y variado puede ser el impacto de esta enfermedad al interior del núcleo familiar. Al fallecer los padres a causa del VIH/SIDA, la familia extendida que decide cuidar a un niño con este diagnóstico, sufre un gran impacto al asumir esta responsabilidad debido a la pena y dolor del niño infectado por el virus, temor al estigma y, en general, la carga económica por las visitas frecuentes al hospital ${ }^{22}$.

La herramienta "Mi Dragón Dormido" demostró eficacia para explicar a los niños su situación de seropositividad para VIH, debido a que facilita la identificación del personaje principal con la propia realidad del paciente. Además, la historia permite que profesionales de la salud puedan desarrollar una estrategia de comunicación terapéutica con los menores a través de un lenguaje sencillo y adaptado a las necesidades de los mismos. Adicionalmente, es una herramienta válida para apoyar en la resolución de preguntas difíciles frente al manejo de esta condición crónica de salud. También esta herramienta puede ser utilizada con niños que no presenten el diagnóstico de infección por VIH para favorecer estrategias preventivas, 
el conocimiento de qué es y qué no es el VIH y favorecer comportamientos de aceptación a la población seropositiva para VIH. Ésta puede considerarse una herramienta complementaria al Modelo Clínico “DIRÉ”, cuyo objetivo principal es favorecer el ajuste psicológico y la adherencia terapéutica de niños y adolescentes bajo17 años de edad diagnosticados con infección por VIH/SIDA a través de 16 sesiones clínico-educativas, que involucran tanto la participación del niño o adolescente como de su cuidador principal y, procesos lúdicos, que buscan prepararlos para que asimilen la enfermedad y facilitar la comprensión del diagnóstico.

Con la validación de este material de apoyo se pretende reforzar las intervenciones que realizan profesionales de la salud, padres y/o cuidadores y educadores para el proceso de revelación y educación del diagnóstico de infección por VIH/SIDA a pacientes bajo 15 años de edad. En general, tanto los profesionales de la salud, cuidadores y niños aceptaron la herramienta, en cuanto a sus colores, imágenes, temas tratados, acciones e identificación de imágenes; además, dieron aportes importantes para la posible utilización de la herramienta no sólo con población diagnosticada con el VIH sino también con niños sin el diagnóstico. En este sentido, la herramienta demostró utilidad para propiciar una reflexión del principio de la igualdad y no discriminación a los pacientes con infección por VIH/SIDA. Es bien sabido que los niños aprenden lo que escuchan en el hogar y en el colegio; por lo tanto, padres de familia y docentes pueden utilizar esta herramienta para trabajar los prejuicios y temores hacia las personas con este diagnóstico a fin de que puedan generar procesos de educación a los niños y mostrarles la manera correcta de tratar a las personas con infección por VIH y así aprender a convivir con ellas en ambientes libres de estigma y discriminación por su condición. A futuro, esperamos desarrollar otras herramientas de apoyo similares a ésta que faciliten el trabajo que se realiza con esta población afectada por el VIH/SIDA.

\section{Referencias bibliográficas}

1.- World Health Organization. Guidelines on HIV disclosure for children up to 12 years of age. 2011. Disponible en: http://whqlibdoc. who.int/publications/2011/9789241502863_ eng.pdf.

2.- American Academy of Pediatrics. Disclosure of illness status to children and adolescents with HIV infection. Pediatrics. 1999; 103: 164-6. doi: 10.1542/peds.103.1.164.

3.- Programa Conjunto de las Naciones Unidas sobre el VIH/SIDA [ONUSIDA]. Hoja Informativa 2015. 2015. Disponible en: http:// www.unaids.org/sites/default/files/media asset/20150901_FactSheet_2015_es.pdf.

4.- Abebe W, Teferra S. Disclosure of diagnosis by parents and caregivers to children infected with HIV: Prevalence associated factors and perceived barriers in Addis Ababa, Ethiopia. AIDS Care 2012; 24(9): 1097-102. doi: 10.1080/09540121.2012.656565.

5.- Atwiine B, Kiwanuka J, Musinguzi N, Atwine D, Haberer J E. Understanding the role of age in HIV disclosure rates and patterns for HIV-infected children in southwestern Uganda. AIDS Care, [serie en Internet]; 2015; 27(4): 424-30. doi: 10.1080/09540121.2014.978735.

6.- Bhattacharya M, Dubey A P, Sharma M. Patterns of diagnosis disclosure and its correlates in HIV-infected north Indian children. J Trop Pediatrics 2015; 57(6): 405-11. https://doi.org/10.1093/tropej/fmq115.

7.- Brown B J, Oladokun R E, Osinusi K, Ochigbo S, Adewole IF, Kanki P. Disclosure of HIV status to infected children in a Nigerian HIV Care Programme. AIDS Care. 2011; 23(9): 1053-8. doi: 10.1080/09540121.2011.554523.

8.- John-Stewart G C, Wariua G, BeimaSofie K M, Richardson B A, Farquhar C, Maleche-Obimbo E, et al. Prevalence, perceptions, and correlates of pediatric HIV disclosure in an HIV treatment program in Kenya. AIDS Care. 2013; 25(9): 1067-76. doi: 10.1080/09540121.2012.749333.

9.- Kallem S, Renner L, Ghebremichael M, Paintsil E. Prevalence and pattern of disclosure. of HIV status in HIV-infected children in Ghana. AIDS Behav 2011; 15(6): 1121-7. https://doi. org/10.1007/s10461-010-9741-9.

10.- Mahloko J M, Madiba S E. Disclosing HIV diagnosis to children in Odi district, South Africa: reasons for disclosure and nondisclosure. Afr J Prim Health Care Fam Med 2012; 4(1): a345. https://doi.org/10.4102/ phcfm.v4i1.345.

11.- Mumburi L P, Hamel B C, Philemon R N, Kapanda G N, Msuya L J. Factors associated with HIV-status disclosure to HIV-infected children receiving care at Kilimanjaro Christian Medical Centre in Moshi, Tanzania. Pan African Med J 2014; 18: 50. doi: 10.11604/ pamj.2014.18.50.2307.

12.- Negese D, Addis K, Awoke A, Birhanu Z, Muluye D, Yifru S, et al. HIV-positive status disclosure and associated factors among children in North Gondar, Northwest Ethiopia. Isrn Aids, 2012. Article ID 485720. https://doi. org/10.5402/2012/485720.

13.- Vaz L M E, Maman S, Eng E, Barbarin O A, Tshikandu T, Behets F. Patterns of disclosure of HIV status to infected children in a Sub-Saharan African setting. J Dev Behav Pediatr, 2011; 32(4): 307-15. doi.org/10.1097/ DBP.0b013e31820f7a47.

14.- Vreeman R C, Nyandiko W M, Ayaya S O, Walumbe E G, Marrero D G, Inui T S. The perceived impact of disclosure of pediatric HIV status on pediatric antiretroviral therapy adherence, child well-being, and social relationships in a resource-limited setting. AIDS Patient Care STDS. 2010; 24(10). https:// doi.org/10.1089/apc.2010.0079.

15.- Trejos A M, Mebarack M, Alarcón-Vásquez Y, Pino M. Validación de una herramienta para revelar diagnóstico de VIH a niños, niñas y adolescentes. Rev Fac Med 2019; 67 (1): 37-43. https://doi.org/10.15446/revfacmed. v67n1.65645.

16.- Trejos A M. Mi dragón dormido. Editorial Universidad del Norte: Barranquilla; 2017. ISBN 978-958-741-756-2 (impreso). 978-958741-757-9 (pdf). https://editorial.uninorte.edu. co/gpd-mi-dragon-dormido.html.

17.- Trejos A M, Reyes L, Bahamon M J, Alarcón Y, Gaviria G. Efectos en la adherencia al tratamiento y en el ajuste psicológico luego de la revelación del diagnóstico de VIH/SIDA con el modelo clínico "DIRÉ" en niños y jóvenes colombianos menores de 17 años. Rev Chilena Infectol 2015; 32 (4): 408-15. http://dx.doi. org/10.4067/S0716-10182015000500007.

18.- Hernández-Sampieri R, Fernández Collado C, Baptista Lucio M. del P. Metodología de la investigación. 6ta Edición. McGraw-Hill: México; 2014. https://periodicooficial.jalisco. gob.mx/sites/periodicooficial.jalisco.gob.mx/ 
org/peru/media/2436/file/Video\%20 Validaci $\% \mathrm{C} 3 \% \mathrm{~B} 3 \mathrm{n} \% 20 \mathrm{de} \% 20$ Materiales.pdf roberto_hernandez_sampieri.pdf

19.- Galeano M. Estrategias de innovación social cualitativa. La carreta editores: Medellín. 2004.

20.- UNICEF. Guía metodológica y video de validación de materiales IEC. Ebrasa: UNICEF Perú. 2003 https://www.unicef.
1.- Tasker M. How can I tell you? Secrecy and disclosure with children when a family member has AIDS. Bethesda, MD: Association for the Care of Children's Health; 1992. https://files. eric.ed.gov/fulltext/ED360768.pdf.
22.- Beauchamp B, Flores L, Lugo L, Robles L, Salabarría I. Sida Pediatrico: Experiencia en el Hospital Pediatrico Universitario. En: Cunningham I, Ramos-Bellido C, Ortíz R. (Eds.). El SIDA en Puerto Rico: Acercamientos Multidisciplinarios, Puerto Rico: Editorial Estudio Gráfico Universal; 1991. p. 175-194.

\section{PRIMER VIAJE AL ESPACIO*}

Primer día en el espacio y no estoy seguro si las personas que viajan junto a mí sonríen o no, al menos yo, si lo hago. A veces pienso que tienen miedo y ansiedad, de no saber si algún día volverán a pisar la tierra, abrazar a sus familias y verlos al rostro; de ser así los entiendo, pero también entiendo, que ésta es la única forma que podemos estar seguros acá. Nadie sabe cuánto tiempo durará esta misión y nuestro mayor desafío consistirá en transmitir con la voz y señas, lo que antes el corazón podía transmitir con sonrisas.

ASTRONAUTA

*Segundo Premio en el Concurso de Cuentos: "Yo, el COVID y la Seguridad del Paciente en 100 palabras". Fundación para la Seguridad del Paciente, Chillán, Ñuble, Chile. 2021. Reproducido con autorización de los Editores 